Gonzalez, R. '; Nishiya, A.T.'; Moreira, M.A.B. '; Eimantas, G. '; Jericó, M.M.'; Bottazzo, R. ${ }^{2}$; Silveira, E.C. ${ }^{2}$ avaliados em todos os animais, antes, 7,14 e 21dias após a inoculação. Foram observadas prostração discreta, febre nos quatro primeiros dias e esplenomegalia moderada do $3^{\circ}$ ao $16^{\circ}$ dia em oito entre os dez càes que receberam o inóculo. A despeito da exaustiva análise do esfregaço do sangue colhido do bordo auricular ou por punção da veia radial, não se observou parasitemia. Também não houve alteração no eritrograma ou na contagem de plaquetas. Houve ascensão do título de anticorpos em todos os cães inoculados, observados 7 dias após a inoculação (título $=640$ ), alcançando o pico em 14 dias (título $=1280$ ). Aparentemente, houve reinfecção dos animais, conforme se verificou pela febre, esplenomegalia e aumento do titulo de anticorpos, apesar da ausência de alteraçòes hematológicas. A infecção foi, provavelmente, restrita pela atividade do Sistema Mononuclear Fagocítico e confinada ao baço, o que se constituiu no estímulo antigênico para o reforço da imunidade humoral.

\section{4 - Utilização de Azatioprina no tratamento de Trombocitopenia imunomediada em cão}

1- Faculdade de Medicina Veterinária da Universidade Anhembi Morumbi, São Paulo-SP

2- Graduação da Faculdade de Medicina Veterinária da Universidade Anhembi Morumbi, São Paulo-SP

A Trombocitopenia imunomediada é afecção comum no cào. A média de idade dos animais acometidos é de 5 a 6 anos, sendo as fêmeas mais comumente afetadas. Presume-se que a patogênese da diminuição do número de plaquetas circulantes seja secundária ao aumento da fagocitose plaquetária no interior do baço, medula óssea e figado, ou à redução na produção de plaquetas secundária à destruição imunomediada de megacariócitos no interior da medula óssea. Classicamente,utilizam-se glicocorticóides como terapia imunossupressora. O uso da azatioprina tem sido associado ao tratamento da anemia hemolítica imunomediada, porém poucos são os casos relatados na literatura compilada para a trombocitopenia imunomediada. Um cão da raça Cocker Spaniel, 5 anos, macho foi apresentado ao Serviço de Clinica Médica do Hospital Veterinário da Universidade Anhembi Morumbi com sintomas de sangramento gengival e epistaxe com evolução de dois dias. Ao exame fisico, o animal apresentava-se alerta, hidratado e com mucosas aparentes hipocoradas e, à inspeçào da cavidade oral, periodontite severa . Durante a consulta, observou-se epistaxe importante. Seus exames laboratoriais (função renal, função hepática, glicemia e urinálise ) apresentaramse dentro dos parâmetros de normalidade. Radiografia torácica e ultrassom abdominal nào revelaram alterações dignas de nota. No hemograma, anemia macrocitica hipocrômica severa $(\mathrm{Ht}=12 \%)$ e trombocitopenia $\left(17000\right.$ plaquetas $\left./ \mathrm{mm}^{3}\right)$. Procedeu-se à transfusão sanguinea com $380 \mathrm{ml}$ de sangue fresco. Apesar da pesquisa de hematozoários ter sido negativa, a abordagem terapêutica inicial foi a administração de dipropionato de imidocarb $(5 \mathrm{mg} / \mathrm{kg} /$ $\mathrm{SC})$ e prescrição de doxiciclina $(5 \mathrm{mg} / \mathrm{kg} / \mathrm{BID})$, uma vez que havia histórico de ixodidiose recente. Além do tratamento antibiótico, instituiu-se terapia imunossupressora com prednisona ( $2 \mathrm{mg} / \mathrm{kg} / \mathrm{SID}$ ). O quadro permaneceu estável e, após 96 horas, o hematócrito do animal era $35 \%$ e sua contagem plaquetária era de 189.000 plaquetas $/ \mathrm{mm}^{3}$. O tratamento com doxiciclina foi mantido durante 21 dias e a segunda aplicação de imidocarb foi realizada 15 dias após a primeira aplicação, seguindo o protocolo de tratamento de hemoparasitose. Prednisona na dose de $2 \mathrm{mg} / \mathrm{kg} / \mathrm{SID}$ foi mantida durante 20 dias, quando foi iniciada a redução gradual da dose. Neste momento, o hematócrito e a contagem plaquetária estavam dentro da normalidade $\left(\mathrm{Ht}=37 \%\right.$ e 211.000 plaquetas $\left./ \mathrm{mm}^{3}\right)$. Após 30 dias do primeiro atendimento, quando a dose diária de prednisona era de $0,75 \mathrm{mg} / \mathrm{kg} / \mathrm{SID}$, a plaquetometria do animal caiu para 59.000 plaquetas $/ \mathrm{mm}^{3}$ e seu hematócrito permaneceu normal $(\mathrm{Ht}=$ $39 \%$ ), momento em que foi reiniciada a dose imunossupressora de prednisona $2 \mathrm{mg} / \mathrm{kg} /$ SID, restabelecendo-se os valores plaquetários normais 4 dias após a reinstituiçào da corticoideterapia. Tentativas posteriores de redução da dose de prednisona levaram novamente a queda na contagem de plaquetas, apesar do hematócrito ter permanecido sempre estável. 
Desta forma, iniciou-se administração de azatioprina na dose de $2 \mathrm{mg} / \mathrm{kg} / \mathrm{SID}$ durante 7 dias, observando-se manutenção da contagem plaquetária $\left(235.000 / \mathrm{mm}^{3}\right)$. A dose de azatioprina foi reduzida semanalmente até $0,7 \mathrm{mg} / \mathrm{kg} / \mathrm{cada} 48$ horas, com plaquetometria dentro da normalidade. $\mathrm{O}$ animal está há 70 dias recebendo esta dose de manutenção de azatioprina exclusivamente e não apresentou sintomas relacionados a efeitos colaterais. Até o momento, a droga mostrou-se uma boa alternativa na manutenção de pacientes que necessitem de terapia imunossupressora crônica.

\section{5 - Acupuntura e fitoterapia chinesa como medicina complementar em alterações locomotoras em cães. Relato de 3 casos}

Hayashi,A.M.'; Shiguihara, C.A.'; Torro, C.A.'

\section{1- CEVEMEC - Centro Veterinário de Medicina Complementar, São Paulo-SP}

A acupuntura representa uma das técnicas de tratamento pela Medicina Tradicional Chinesa(MTC), acompanhada da fitoterapia chinesa e moxabustão. Sào usadas como armas terapêuticas complementares, ou seja em associação ao tratamento clínico ou cirúrgico, por exemplo em discopatias. Em alguns casos onde a resposta ao tratamento convencional nào é satisfatória ou há recidivas, além de impossibilidade de cirurgia(por variados motivos), a MTC pode ser outra forma de abordagem terapêutica. Decidiu-se a realização deste trabalho para demonstrar que a acupuntura associada com a fitoterapia chinesa potencializa o efeito da MTC, obtendo-se melhora clínica mais rápida.. Foram realizados os diagnósticos e tratamentos segundo a MTC em três casos de patologias locomotoras, utilizando-se as duas técnicas citadas, além da moxabustão. Foram feitas 4 sessōes com intervalos de 7 dias e depois 2 sessões com intervalos de 14 dias, com exceçào do caso 2 onde se acrescentou 1 sessào, além de iniciar em todos os casos a administração de fitoterapia chinesa logo na $1^{\mathrm{a}}$ semana da acupuntura. As avaliações de evolução clínica foram feitas sempre 1 semana após a sessão ter sido realizada. $\mathrm{O}$ caso 1 relata uma cadela de 5 anos que apresentava há 2 meses impotência funcional de membros posteriores com diagnóstico radiográfico de discopatia, com crises anteriores, há mais de 1 ano.Apresentava resposta ao estímulo doloroso, atrofia muscular discreta, teve infecção do vírus da cinomose quando filhote, doença que pela MTC leva a um grande desgaste energético.Neste animal foram utilizados os seguintes pontos, dependendo da sessão : ID3, B62, R3/B60, BP6,VB39,VB34, E36, F8 com agulhas e estimulação manual, e os pontos B23 e VG4 com agulhas e moxabustão, e os pontos B20, B17 com moxabustão. Usadas fórmulas magistrais chinesas : Guei Fu Di Huang Wan e Gui Pi Tang. Logo na $1^{2}$ semana conseguiu apoiar e dar alguns passos, evoluindo bem a cada sessão, até locomoção normal. $\mathrm{O}$ caso 2 relata uma cadela de 5 anos com lombalgia crônica e impotência funcional de membros posteriores por discopatia, última crise há 2 meses, apresentando incontinência urinária, resposta ao estímulo da dor, porém diminuída no MPD.Os pontos usados são os mesmos do caso anterior, exceto B17, F8 e E36 e acrescentados VB30 e B28.Logo na $1^{2}$ semana observou-se andar atáxico intermitente, propriocepçaõ diminuida no MPD e mantendo-se em estação com facilidade, com melhora clínica a cada sessão incluindo a incontinência urinária, estabilização da locomoção atáxica discreta dos membros posteriores.As fórmulas usadas, segundo avaliaçào semanal foram: Bu Yang Huan Wu Tang, Xiao Huo Luo Dan, além das duas fórmulas do caso 1. O caso 3 relata um cão Rottweiler de 8 anos com síndrome cérvico-torácica há 1 semana sem resposta medicamentosa, com incapacidade de se manter em estação, hiperreflexia de membros posteriores e hiporreflexia e discreta resposta à dor em membros torácicos(mais evidente no esquerdo).Os pontos usados: ID3,B62,R3/B60,BP6/VB39,B17, BP10,IG4,IG15 e agulha e moxa em B23,VG4,VG14 e B12 conforme avaliação clínica.Fitoterapia chinesa: Du Huo Ji Shen Tang, Guei Fu Di Huang Wan, Angélica sinensis,Bu Yang Huan Wu Tang, Gui Pi Tang. Na $1^{2}$ semana, animal conseguiu se locomover, com claudicação discreta do membro torácico esquerdo, evolução boa a cada sessão.Podemos observar que estas terapias associadas 